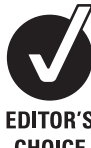

CHOICE

${ }^{1}$ Department of Pathology,

University of California, San

Francisco, California, USA;

${ }^{2}$ Department of Pathology,

University of California, San

Francisco, and Veterans Affairs

Medical Center, San Francisco,

California, USA

Correspondence to:

Dr Sanjay Kakar, Department of Pathology, UCSF and VA

Medical Center, San Francisco,

CA 94143, USA; sanjay.kakar@ ucsf.edu

Accepted 19 December 2008

\title{
Histological patterns in drug-induced liver disease
}

\author{
R Ramachandran, ${ }^{1}$ S Kakar ${ }^{2}$
}

\begin{abstract}
The diagnosis of drug-induced liver injury (DILI) is a challenging problem, often confounded by incomplete clinical information and the difficulty of eliciting exposure to herbal products, over-the-counter agents and toxins. The task is further rendered difficult on biopsy, as drugs can mimic all the patterns found in primary liver disease. Acute hepatitis, with or without cholestasis, is the most common histological pattern of DILI, and drugs such as acetaminophen are the leading causes of acute liver failure. Most cases of DILI resolve on discontinuation of the drug, but recovery can take months or rarely the disease can progress despite drug withdrawal. Drugs such as methotrexate can lead to chronic hepatitis and cirrhosis, while others such as minocycline, nitrofurantoin and methyldopa are implicated in autoimmune hepatitis. Prolonged cholestasis and ductopenia resembling primary chronic biliary disease can occur. Drug-induced steatohepatitis is also an uncommon pattern, but is well described with drugs such as amiodarone and irinotecan. In the presence of risk factors such as obesity and diabetes, some drugs such as tamoxifen, oestrogens and nifedipine can precipitate or exacerbate steatohepatitis. Other observed patterns include granulomatous hepatitis, vascular injury (eg, sinusoidal obstruction syndrome), Ito cell lipidosis and neoplasms (eg, adenomas).
\end{abstract}

Evaluation of liver biopsy for adverse drug reaction is one of the most challenging problems in liver pathology. Drug-related injury can mimic all the patterns observed in primary liver disease, and an unequivocal histological diagnosis is not possible in the majority of cases. Inadequate clinical history and multiple drugs being taken simultaneously often compound the problem. It can be difficult to elicit information about herbal agents, over-thecounter medications, and exposure to household or industrial toxins. The list of drugs associated with hepatotoxicity is long, although the association of many drugs with liver injury remains tenuous and can be found only in case reports.

\section{MECHANISMS OF INJURY}

It is widely recognised that drug-induced liver injury (DILI) is mediated by two chief mechanisms: intrinsic and idiosyncratic hepatoxicity. Intrinsic hepatotoxins cause hepatocellular damage in a predictable dose-dependent manner directly by the drug or indirectly by its metabolite. Some drugs, such as acetaminophen, cause intrinsic hepatotoxicity, but the majority of agents in this category are industrial, household or environmental toxins such as carbon tetrachloride and alkaloids in mushrooms. The majority of drugs lead to idiosyncratic liver injury and can be classified into metabolic and immunological categories. In the former, the drug is metabolised into a toxic metabolite in predisposed individuals, while the latter is akin to "drug allergy" or hypersensitivity following sensitisation to the drug. In general, intrinsic hepatotoxicity manifests with hepatocellular necrosis with little inflammation, while idiosyncratic drug reactions often show inflammation-dominant hepatic injury.

\section{ESTABLISHING DRUG AS THE CAUSATIVE AGENT}

The temporal profile is crucial to establish the diagnosis of DILI, as the onset of liver disease follows drug ingestion. However, the manifestation of liver toxicity may occur weeks or months after drug ingestion and even after the drug has been stopped. Liver enzyme elevations can persist for up to several months after the drug has been discontinued. In some instances, measurement of serum levels of the drug or its metabolite can be helpful in diagnosis, such as in acetaminophen toxicity. Since the list of drugs capable of causing liver injury is long, a systematic literature search for each drug that the patient has been taking is necessary. The case for DILI is strengthened if the reported pattern of injury in the literature is in keeping with the observed clinical and histological picture. Rechallenge with the drug can help establish the drug aetiology, but it is often not done due to the inherent risk involved. Since diverse histological patterns of DILI can mimic virtually any primary liver disease, appropriate imaging and laboratory tests are necessary to exclude other aetiologies before the diagnosis of DILI can be accepted.

Liver injury can be classified as hepatocellular, cholestatic or mixed, based on criteria established by the Council for International Organizations of Medical Sciences (CIOMS) ${ }^{12}$ (table 1).

The CIOMS system also is used for causality assessment of DILI by scoring parameters such as time to onset of symptoms, laboratory data, additional drug regimen, known toxicity of suspected drug, non-drug causes, and response to rechallenge. The total score is categorised into ranges of causality: highly probable, probable, possible, unlikely and excluded. ${ }^{3-5}$ The remaining discussion is devoted to the patterns observed in DILI with emphasis on morphological features, common drugs and differential diagnosis for each pattern (table 2).

\section{ACUTE HEPATITIS}

DILI accounts for $\sim 10 \%$ of acute hepatitis and is perhaps the most common cause of cholestatic hepatitis. ${ }^{6}$ A wide variety of drugs can cause acute hepatocellular injury (box 1).

Herbal and botanical drugs are an important but often overlooked cause of hepatotoxicity (table 3). 
Table 1 CIOMS consensus criteria for terminology in drug-induced liver injury

\begin{tabular}{ll}
\hline Terminology & Criteria \\
\hline Hepatocellular injury & Isolated increase in ALT $>$ twice normal, or ALT/ALP $\geqslant 5$ \\
Cholestatic injury & Isolated increase in ALP $>$ twice normal, or ALT/ALP $\leqslant 2$ \\
Mixed injury & ALT and ALP are increased, and $2<A L T / A L P<5$ \\
Acute injury & Above changes present for $<3$ months \\
Chronic injury & Above changes present for $>3$ months \\
Chronic liver disease & This term is used only after histological confirmation
\end{tabular}

ALP, alkaline phosphatase; ALT, alanine aminotransferase; CIOMS, Council for International Organizations of Medical Sciences.

These are not regulated by the Food and Drug Administration and hence are not subject to rigorous testing. More than 20000 herbal products are marketed in forms including powders, essential oils and teas, and more than $\$ 5$ billion are spent on these annually. Nearly $20 \%$ of American adults have used herbal remedies, and usage is higher in selected groups including Chinese, $^{20}$ South African ${ }^{21}$ and Native American ${ }^{22}$ cultures. Definitive identification of an herbal product can require chemical analysis, as mistranslation or misidentification can be an issue. Eliciting a detailed herbal history is imperative. ${ }^{23}$ Certain commonly consumed herbal agents now being investigated for their hepatoprotective effects, such as turmeric (Curcuma longa ${ }^{24}$ and mate tea (Ilex paraguariensis), ${ }^{25}$ are listed as potentially hepatotoxic in various patient literature. Finally, contaminants of herbal supplements should be considered, including heavy metals such as arsenic, cadmium, lead or mercury. ${ }^{26}$

The following morphological patterns can be observed in acute hepatocellular injury.

- Acute hepatitis. The hallmarks of acute hepatocellular injury are portal and parenchymal inflammation, hepatocellular injury, and/or necrosis (fig 1). By definition, fibrosis is absent. Regenerative features such as binucleate hepatocytes and thick cell plates are common. Prominent Kupffer cells often are present in the sinusoids. The term "cholestatic hepatitis" is used when these changes are accompanied by cholestasis (see Acute cholestatic injury).

- Necrosis. Acute hepatocellular injury can result in necrosis affecting single (spotty necrosis) or groups of hepatocytes (confluent necrosis). In some cases, confluent necrosis can be zonal and may be helpful in diagnosis. Centrizonal (zone 3) necrosis is characteristic of acetaminophen and halothane, and toxins such as carbon tetrachloride. Isolated necrosis affecting zones 1 and 2 is rare; toxins such as cocaine and ferrous sulfate typically affect zone 1 , while beryllium has been implicated in zone 2 necrosis. When extensive, confluent necrosis can lead to acute hepatic failure.

- Resolving hepatitis. If biopsy is performed later in the disease course, hepatocellular injury and inflammation may be minimal (fig 2). The presence of numerous macrophages in the sinusoids is a helpful clue for the diagnosis of resolving hepatitis. The stain periodic acid-Schiff with diastase can be used to highlight the macrophages (fig 3).

Table 2 Overview of drug-induced liver injury patterns

\begin{tabular}{|c|c|c|}
\hline Histological pattern & Differential diagnosis & Common drugs involved \\
\hline Acute hepatitis and cholestatic hepatitis & $\begin{array}{l}\text { Viral hepatitis, autoimmune hepatitis, Wilson disease, } \\
\text { idiopathic }\end{array}$ & See table 3 \\
\hline
\end{tabular}

Acute liver failure

Necrosis with marked inflammation

Autoimmune hepatitis, viral hepatitis, Wilson disease

Necrosis with little or no inflammation

Microvesicular steatosis with little or no inflammation

Chronic hepatitis

Autoimmune marker-negative

Drug-induced autoimmune hepatitis

Cholestasis

Bland cholestasis

Cholestatic hepatitis (cholangiolitic or hypersensitivity cholestasis)

Granulomatous hepatitis

Steatosis/steatohepatitis

Macrovesicular steatosis

Microvesicular steatosis

Steatohepatitis

Vascular abnormalities

Sinusoidal obstruction syndrome
Herpes simplex or adenoviral hepatitis, Wilson disease, malignant infiltration

Acute alcohol intoxication, Reye syndrome, fatty liver of pregnancy

Autoimmune hepatitis. chronic viral hepatitis, Wilson disease Lisinopril, sulfonamides, trazodone, uracil,

Sepsis, cardiac failure, shock, large duct obstruction, benign Anabolic/androgenic steroids, oestrogenic intrahepatic cholestasis, intrahepatic cholestasis of pregnancy steroids, NSAIDs (nimesulide, piroxicam) Viral hepatitis, large duct obstruction

Infections, sarcoidosis, primary biliary cirrhosis, talc, metal toxicity

Diabetes, obesity, Wilson disease, hepatitis C

Fatty liver of pregnancy, carnitine deficiency, Reye syndrome Cocaine, tetracycline, valproic acid, zidovudine (See macrovesicular steatosis differential)

Myeloablation, venous outflow obstruction, right heart disease tegafur, tamoxifen, methotrexate Minocycline, nitrofurantoin, methyldopa, clometacin Chlorpromazine, clarithromycin

Isoniazid, interferon, phenytoin, allopurinol (also see box 2)

Alcohol, steroids, total parenteral nutrition, gold, chlorinated hydrocarbons, chemotherapeutic agents (5-fluorouracil) Amiodarone, chemotherapeutic agents (irinotecan), perhexiline

Isoniazid, monoamine oxidase inhibitors, ketoconazole)

Acetaminophen, cocaine, MDMA (ecstasy) carbon tetrachloride

Tetracycline, nucleoside analogues

Oxaliplatin, pyrrolizidine alkaloids, chemotherapy for ALL

ALL, acute lymphoblastic leukaemia; MDMA, 3,4-methylenedioxymethylamphetamine; NSAID, non-steroidal anti-inflammatory drug 
Box 1 Drugs associated with acute hepatitis pattern of injury

Non-steroidal anti-inflammatory drugs

- Diclofenac*, indomethacin, tolmetin, sulindac, ibuprofen, ketoprofen, mefenamic acid, celecoxib

Anaesthetic agents

- Halothane, ${ }^{7}$ methoxyflurane

Anticonvulsants

- Phenytoin, carbamazepine* ${ }^{*}$, valproic acid, chlorpromazine*

Antibacterial agents

- Ampicillin, amoxicillin-clavulanic acid, ${ }^{5}{ }^{8} 9$ oxacillin, cephalosporins, tetracycline, sulfonamides, erythromycin, trimethoprim-sulfamethoxazole ${ }^{*}$

\section{Antifungal agents}

- Griseofulvin, fluconazole, ketoconazole*

Antiparasitic agents

- Albendazole, thiabendazole, fansidar

Antituberculous agents

- Isoniazid, rifampin

Antiviral agents

- Zidovudine, ribavirin, nevirapine ${ }^{*}$, efavirenz ${ }^{*}$

Antitumour agents

- 6-Mercaptopurine, azathioprine, L-asparaginase, mithramycin, vincristine, cyclophosphamide, carmustine

Antihypertensive agents

- Methyldopa, hydralazine, lisinopril, labetalol

Antiarrhythmic agents

- Quinidine, nifedipine, procainamide

Hypolipidaemics

- Statins, clofibrate, nicotinic acid, ezetimibe*

Hypoglycaemics*

- Rosiglitazone, troglitazone

Antiandrogens*

- Flutamide

Other

- Sulfonylureas, troglitazone, dantrolene, chlorzoxazone, dextropropoxyphene, allopurinol, gold

\section{Toxins}

- Aflatoxin, death cap mushroom (Amanita phalloides), carbon tetrachloride, ethylene dichloride, allyl compounds, ferrous sulfate, phosphorus, MDMA (ecstasy)

*Primarily cholestatic pattern

\section{Differential diagnosis}

The histological features can be indistinguishable from other causes of acute hepatitis such as acute viral hepatitis, initial presentation of autoimmune hepatitis and Wilson disease. The presence of bile duct injury, prominent eosinophilic infiltrate, granulomas, sharply defined perivenular necrosis, or cholestasis out of proportion to hepatocellular injury, favours adverse drug reaction, but none of these features is specific.

\section{ACUTE LIVER FAILURE (FULMINANT HEPATITIS)}

Acute liver failure (ALF) is defined as the onset of hepatic encephalopathy within 8 weeks of onset of symptoms. Drugs are the most common cause of ALF in the USA, accounting for $25-50 \%$ of cases. ${ }^{27-30}$

Based on morphological features, ALF can be subdivided into three categories.

- Extensive microvesicular steatosis. This pattern is rare and has been observed with tetracycline and nucleoside analogues such as zidovudine (see Steatosis and steatohepatitis).

- Necrosis with marked inflammatory activity. This is the most common pattern seen in idiosyncratic adverse drug reactions. It is similar to the acute hepatitis pattern discussed above except that the confluent necrosis involves most of the liver parenchyma (massive/submassive hepatic necrosis). The most commonly implicated drugs are isoniazid, ${ }^{31} 32$ other antimicrobial agents (sulfonamides, cotrimoxazole, ketoconazole), monoamine oxidase inhibitors, and anticonvulsants (phenytoin, ${ }^{31}$ valproate). Any drug that causes acute hepatitis can potentially cause ALF.

- Necrosis with little or no inflammation. This pattern is seen with acetaminophen (fig 4), recreational drugs such as cocaine and 3,4-methylenedioxymethylamphetamine (MDMA; ecstasy), industrial organic compounds such as carbon tetrachloride, and some herbal preparations. Necrosis can be accompanied by steatosis.

\section{Acetaminophen}

Acetaminophen toxicity is the leading drug-related cause, implicated in nearly $40 \%$ of ALF, the remaining being attributed to idiosyncratic drug reactions. ${ }^{27-29}{ }^{33}$ Acetaminophen is a very safe drug within its therapeutic window (3-4 g/day), but can cause dose-dependent toxicity with overdose whether accidental ( $1 / 3$ of cases) or with suicidal intent ( $2 / 3$ of cases). At low doses, the drug is conjugated to water-soluble metabolites in the liver and is excreted in the urine. At higher doses, glutathione depletion leads to saturation of the conjugation mechanism, leaving the parent compound to be metabolised to toxic intermediates. The minimum toxic dose in adults is $7.5-10 \mathrm{~g}$, but severe liver damage occurs with ingestion of $15-25 \mathrm{~g}$. Acetaminophen blood levels taken 4-16 h after ingestion are the best predictor of outcome. Chronic alcohol consumption, obesity, and drugs that induce the P-450 cytochrome system, such as isoniazid, phenytoin, carbamazepine or cimetidine, can lower the toxic threshold of acetaminophen.

Patients typically experience gastrointestinal symptoms for the first $12-24 \mathrm{~h}$ and a latent phase at $24-48 \mathrm{~h}$. The onset of acute hepatitis/acute liver failure occurs $72-96 \mathrm{~h}$ after drug ingestion. Hepatotoxicity can be prevented with early presentation and institution of acetyl-cysteine therapy within $12 \mathrm{~h}$. The highest mortality is encountered in late presenters.

\section{CHRONIC HEPATITIS}

Chronic liver disease typically refers to persistent biochemical abnormalities beyond 6 months. ${ }^{34}$ In some series, the cut-off of 3 months has been used for hepatocellular injury and 6 months for cholestatic or mixed injury. ${ }^{35}$ Progression to chronicity has been reported in $5-10 \%$ of adverse drug reactions and is higher for the cholestatic/mixed injury pattern. ${ }^{36}$ Histologically proven drug-induced chronic hepatitis with fibrosis is a rare 
Table 3 Herbal products with known hepatotoxicity

\begin{tabular}{|c|c|c|}
\hline Herbal product $^{10}{ }^{11}$ & Intended use & Biopsy findings \\
\hline $\begin{array}{l}\text { Chaparral leaf (creosote bush, Larrea tridentata), }{ }^{12} \text { teas and } \\
\text { capsules }\end{array}$ & Antimicrobial, anti-aging, skin conditions & $\begin{array}{l}\text { Acute hepatitis, cholestasis, hepatocellular } \\
\text { necrosis }\end{array}$ \\
\hline Germander (Teucrium genus), ${ }^{1314}$ teas and tablets & Antiseptic, antipyretic, abdominal ailments, obesity & $\begin{array}{l}\text { Acute hepatitis, centrizonal necrosis, rarely } \\
\text { chronic liver disease with cirrhosis }\end{array}$ \\
\hline $\begin{array}{l}\text { Pennyroyal (Mentha pulegium, Hedeoma pulegioides), }{ }^{15} \\
\text { "squaw mint" oil }\end{array}$ & Emmenagogue, abortifacient, anti-flea agent for pets & Centrizonal necrosis \\
\hline $\begin{array}{l}\text { Glue thistle (Atractylis gummifera) }{ }^{16} \text { found in Mediterranean } \\
\text { region and North Africa }\end{array}$ & Emetic, diuretic, antipyretic & Centrizonal necrosis, panacinar necrosis \\
\hline $\begin{array}{l}\text { Jin bu huan (Lycopodium serratum), }{ }^{17} \text { marketed as anodyne } \\
\text { tablets in 1990s }\end{array}$ & Sleeping aid, analgesic & $\begin{array}{l}\text { Acute hepatitis, chronic hepatitis, } \\
\text { microvesicular steatosis }\end{array}$ \\
\hline Kava (Piper methysticum) $)^{2} 18$ & Stress relief, anti-anxiety, sleeping aid, premenstrual syndrome & Acute hepatitis, fulminant hepatitis \\
\hline Mistletoe (Phoradendron and Viscum geni) ${ }^{19}$ & Digestive aid, heart tonic, sedative & Acute hepatitis \\
\hline
\end{tabular}

phenomenon. Some specific patterns and clinicopathological situations are discussed below.

\section{Chronic hepatitis with negative autoimmune markers}

The histological features are indistinguishable from chronic viral hepatitis, and progression to fibrosis and even cirrhosis can occur. The features of acute hepatitis may be seen to a variable degree. Drugs associated with this pattern include lisinopril (antihypertensive), sulfonamide (antibiotic), trazodone (antidepressant), and chemotherapeutic agents such as uracil, 5fluorouracil prodrug tegafur and tamoxifen. Isolated case reports implicate numerous other drugs including phenytoin ${ }^{37}$ and the Chinese herb Jin bu huan. ${ }^{38}$ Progression to fibrosing cholestatic hepatitis has been reported in a hepatitis $C$ patient after administration of cyclophosphamide and corticosteroids for glomerulonephritis. ${ }^{39}$ Discontinuation of the drug may lead to a favourable outcome, but if the fibrosis is advanced the resolution may be slow or the disease may progress.

\section{Autoimmune hepatitis}

Several drugs can cause chronic hepatitis that is serologically and morphologically indistinguishable from de novo autoimmune hepatitis (AIH). The hepatic disease may be accompanied by features of hypersensitivity such as rash, arthralgia and peripheral eosinophilia.

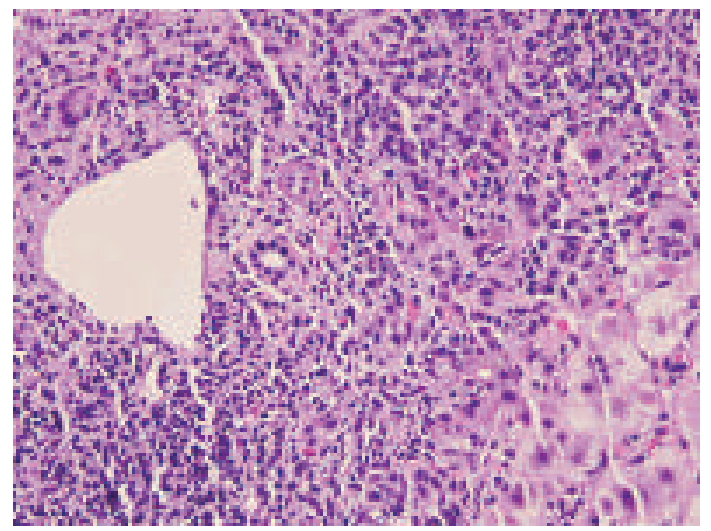

Figure 1 Atorvastatin-induced acute hepatitis. Mixed parenchymal inflammation is present, consisting of lymphocytes, plasmahistiocytic cells, and neutrophils. There is no bile duct damage or fibrosis. H\&E, $\times 200$.

\section{Minocycline}

Long-term use of minocycline, a synthetic tetracycline for treatment of acne, can lead to hepatitis that can mimic lupusrelated hepatitis, AIH or overlap syndrome. Autoimmune disease can develop within days of starting the drug or may be delayed for many years. High titres of antinuclear antibodies (ANAs) are common, but smooth muscle (SMA) and other autoantibodies often are negative. Autoimmune markers may be elevated in chronic hepatitis due to drugs (drug-induced autoimmune hepatitis). Inflammatory activity can be minimal to mild, and eosinophils are typically inconspicuous (fig 5). Marked fibrosis and cirrhosis are rare, and patients often improve after drug withdrawal. ${ }^{40}$ Microvesicular and macrovesicular steatosis in response to minocycline have been reported, but these followed high-dose intravenous therapy rather than oral administration. ${ }^{41}$

\section{Nitrofurantoin}

Nitrofurantoin is used to treat urinary tract infections. The hepatic injury can manifest as self-limited acute hepatitis, chronic hepatitis, and rarely as hepatic failure. ${ }^{42}$ Chronic hepatitis can be indistinguishable from de novo $\mathrm{AIH}$ and is often associated with ANA and SMA. ${ }^{43}$ Discontinuation of the drug generally leads to clinical and biochemical improvement. In some cases, the disease may progress despite drug withdrawal. In contrast to minocycline, significant fibrosis and cirrhosis can occur.

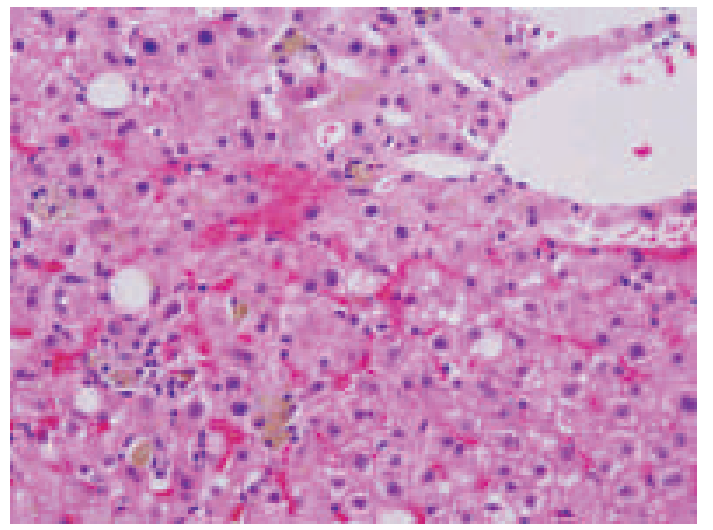

Figure 2 Resolving hepatitis. Parenchymal infiltrate is diminished in comparison to acute hepatitis. Hepatocellular injury is minimal. Pigment accumulation in sinusoidal macrophages is prominent. H\&E, $\times 200$. 


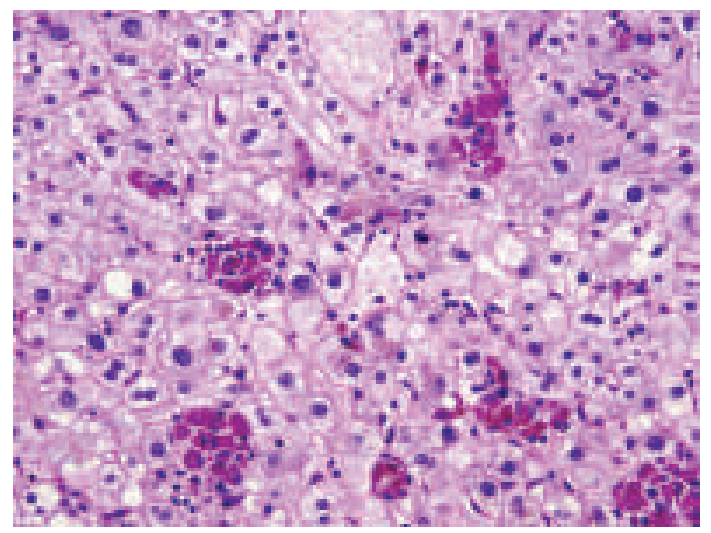

Figure 3 Resolving hepatitis. Sinusoidal macrophages are evident with periodic acid-Schiff (PAS)-positive diastase-resistant cytoplasmic contents. PAS with diastase, $\times 200$.

\section{Others}

Other drugs implicated in AIH include methyldopa (antihypertensive $)^{44}$ and clometacin non-steroidal anti-inflammatory drug (NSAID). ${ }^{45}$ Antibodies to liver-kidney-microsomal antibodies, akin to type $2 \mathrm{AIH}$, have been described in hepatitis related to hydralazine (antihypertensive) and tienilic acid (ticrynafen, a diuretic withdrawn from the American market), but this association is not clearly defined. ${ }^{46}$

\section{Methotrexate}

Methotrexate is a folate antagonist that is used for long-term treatment of rheumatoid arthritis, psoriasis and inflammatory bowel disease. The canals of Hering may be the target of methotrexate-related scarring. ${ }^{47}$ The risk of liver toxicity is exacerbated with heavy alcohol use, pre-existing liver disease, daily dosing and high cumulative dose. ${ }^{48}$ Minor elevation in liver enzymes occurs in $20-50 \%$ of patients but does not necessarily imply significant toxicity.

The histological features of methotrexate-related toxicity range from minor fatty change, hepatocyte anisonucleosis, mild portal-based inflammation, and focal necrosis to more severe hepatocellular necrosis, fibrosis and cirrhosis (fig 6). Methotrexate may exacerbate or precipitate steatohepatitis in patients with risk factors such as obesity and diabetes. Some patients with high cumulative dose can have steatohepatitis-like histology without other risk factors. ${ }^{49}$

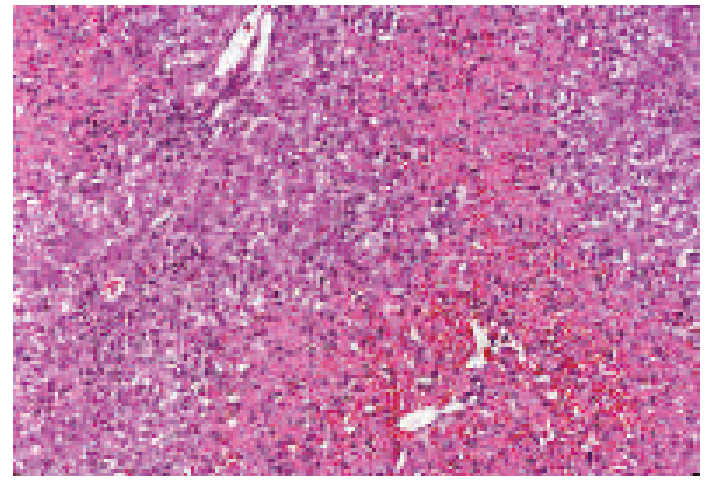

Figure 4 Acetaminophen toxicity. Marked hepatocellular necrosis is present in a zonal, centrilobular pattern, while the inflammatory infiltrate is minimal. Residual viable hepatocytes show some steatosis. H\&E,

$\times 100$. (Image courtesy of Dr Linda Ferrell, University of California, San Francisco, California, USA.)

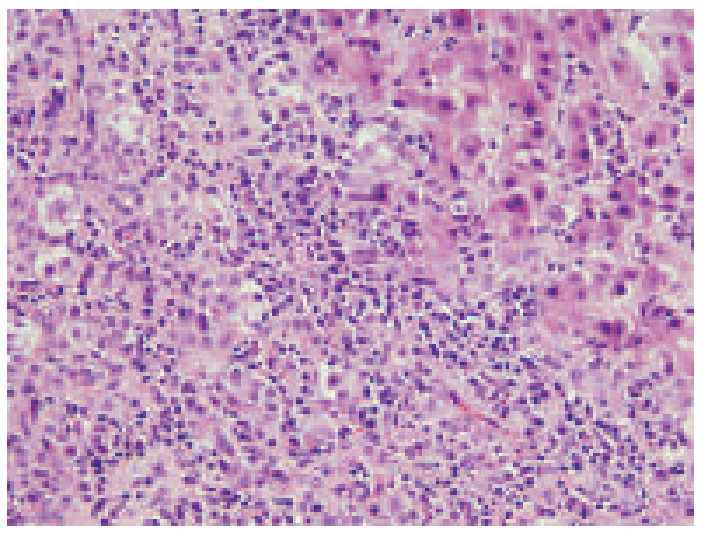

Figure 5 Minocycline-induced autoimmune hepatitis. Marked necroinflammatory activity with numerous plasma cells. $\mathrm{H \& E}, \times 200$.

Patients on long-term methotrexate need close monitoring. Liver biopsy is necessary in patients who develop deranged liver function following methotrexate therapy. A grading scheme has been proposed to assess toxicity (Roenigk classification ${ }^{50-52}$; table 4).

\section{ACUTE CHOLESTATIC INJURY}

Drug-induced cholestatic injury can manifest clinically with jaundice, pruritus, dark urine and pale stools. Liver enzyme studies typically reveal elevation of alkaline phosphatase and $\gamma$ glutamyl transferase. Transaminases can be variably elevated. A Danish study of 1100 cases of drug-associated injury reported $16 \%$ with the acute cholestatic pattern. ${ }^{53}$

The histological patterns of injury can be divided into two forms. (1) Pure (bland) cholestasis in which bile plugs are seen in hepatocytes or canaliculi and are most prominent in zone 3. Inflammation and hepatocellular injury are not observed. This pattern is typically observed with anabolic steroids (fig 7) and oral contraceptives. Other drugs that have been incriminated include prochlorperazine, thiabendazole $e^{54}$ and warfarin. (2) Cholestatic hepatitis in which the cholestasis is accompanied by inflammation and hepatocellular injury. Bile ductular reaction may be present. This pattern also has been referred to as cholangiolitic or hypersensitivity cholestasis. ${ }^{55}$ This pattern manifests as mixed-type injury on liver biochemical tests.

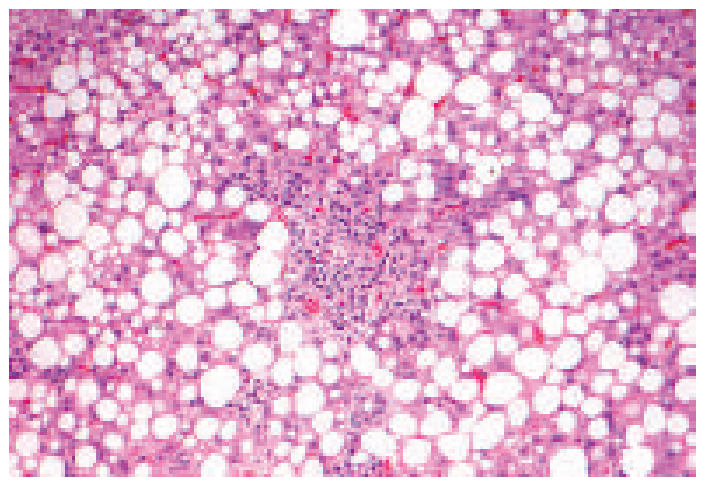

Figure 6 Methotrexate toxicity. Prominent macrovesicular steatosis and periportal fibrosis. H\&E, $\times 100$. (Image courtesy of Dr Linda Ferrell, University of California, San Francisco, California, USA.) 
Table 4 Roenigk classification system ${ }^{51}$

\begin{tabular}{lllll}
\hline Roenigk grade & Fatty change & Nuclear pleomorphism & Necroinflammatory damage & Fibrosis \\
\hline I & Mild or none & Mild or none & Mild or none & None \\
II & Moderate or severe & Moderate or severe & $\begin{array}{l}\text { Moderate or severe portal } \\
\text { inflammation }\end{array}$ & None \\
IIla & With or without & With or without & With or without & Mild \\
IIIb & With or without & With or without & With or without & $\begin{array}{l}\text { Moderate or } \\
\text { severe }\end{array}$ \\
IV & With or without & With or without & With or without & Cirrhosis \\
\hline
\end{tabular}

A score of IIIb or IV is an indication to discontinue the drug. Early detection and discontinuation of the drug is associated with a favourable outcome.

Cholestatic hepatitis can result from a wide variety of drugs; it is the classic pattern seen with toxicity due to macrolide antibiotics such as erythromycin ${ }^{56}$ (fig 8) and the antipsychotic agent chlorpromazine (see box 1).

\section{Differential diagnosis}

Drug-induced cholestatic injury can be histologically indistinguishable from obstructive biliary disease. While the latter typically results in portal tract oedema and ductular reaction with inflammation, cholestasis may be the only significant feature in early stages. Drug-induced cholestatic hepatitis also needs to be distinguished from autoimmune hepatitis and acute viral hepatitis.

Bland cholestasis can occur in several systemic disorders such as sepsis, cardiac failure and shock, and hence clinical information is necessary to establish the aetiology. In the appropriate clinical setting, benign recurrent intrahepatic cholestasis, postoperative cholestasis and intrahepatic cholestasis of pregnancy have to be considered. Benign recurrent intrahepatic cholestasis is a mild, non-progressive variant of bile transporter disorder characterised by intermittent episodes of cholestasis. ${ }^{57}$ Intrahepatic cholestasis of pregnancy also is due to bile transporter gene variation, although it additionally appears affected by hormonal status, as twin pregnancies and patients on oral contraceptives are reported to be more susceptible to intrahepatic cholestasis of pregnancy. ${ }^{58}$

Chronic biliary diseases such as primary biliary cirrhosis and primary sclerosing cholangitis do not show cholestasis on biopsy early in the course of the disease; serological tests such as antimitochondrial antibodies and cholangiography, respectively, can more definitely rule out these diagnoses.

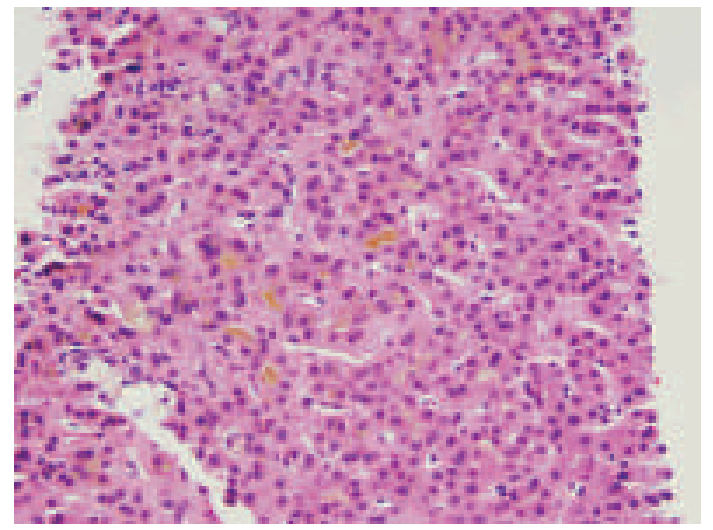

Figure 7 Anabolic-steroid-induced pure cholestasis. Prominent bile plugs are present in hepatocytes and canaliculi without inflammation or hepatocellular damage. H\&E, $\times 200$.

\section{CHRONIC CHOLESTASIS AND DUCTOPENIA}

Cholestatic symptoms and biochemical findings usually resolve with cessation of the offending drug but may persist in some instances. Drugs causing prolonged cholestasis (defined as greater than 3 months in duration) $)^{159}$ and ductopenia include antibiotics such as amoxicillin-clavulanic $\operatorname{acid}^{60}{ }^{61}$ and flucloxacillin, $^{6263}$ antifungals such as terbinafine ${ }^{64}$ and, rarely, oral contraceptives. ${ }^{65}$ Amiodarone can also cause prolonged disease. ${ }^{66}$

\section{Vanishing bile duct syndrome}

Cholestasis with variable degree of inflammation, bile duct injury and hepatocellular damage is seen early in the course of the disease (fig 9). If the disease persists for a few months or beyond, loss of bile ducts and overt ductopenia may be observed, termed "vanishing bile duct syndrome". Persistent inflammation and bile ductular reaction also may be present. Rare cases can progress to cirrhosis. Vanishing bile duct syndrome can be triggered by anticonvulsants such as carbamazepine ${ }^{67}$ and zonisamide, ${ }^{68}$ antipsychotics such as chlorpromazine $^{69}$ and sulpiride, ${ }^{70}$ NSAIDs such as ibuprofen ${ }^{71}$ and tenoxicam, ${ }^{73}$ and antibiotics such as amoxicillin, ${ }^{74}$ flucloxacillin, ${ }^{75}$ clindamycin and trimethoprim-sulfamethoxazole. ${ }^{76}$ The histological picture can mimic primary biliary cirrhosis or obstructive biliary disease. Absence of antimitochondrial antibodies and normal imaging of the biliary tree help in establishing drug-related aetiology.

\section{Other patterns}

Biliary sclerosis can result from intra-arterial infusion of 5fluorodeoxyuridine for treatment of hepatic metastasis of colorectal carcinoma. ${ }^{77}$ Ischaemic injury to the large intrahepatic and extrahepatic bile ducts can lead to strictures that resemble

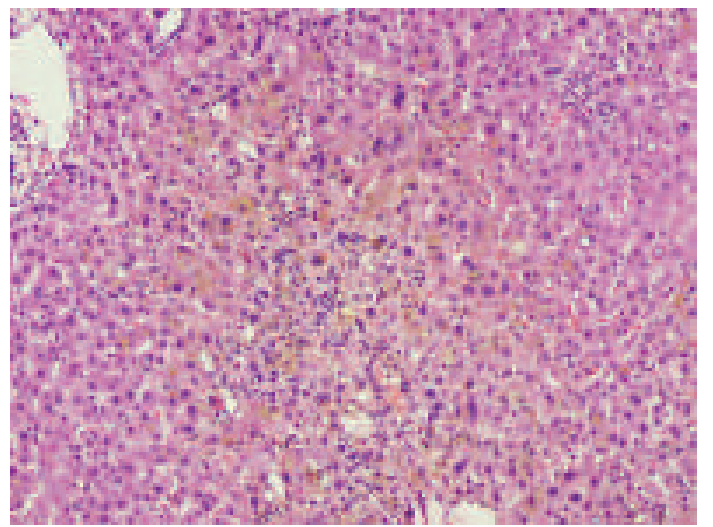

Figure 8 Erythromycin-related cholestatic hepatitis. Features similar to acute hepatitis are present, as well as bile plugs in hepatocytes and canaliculi. H\&E, $\times 100$. 


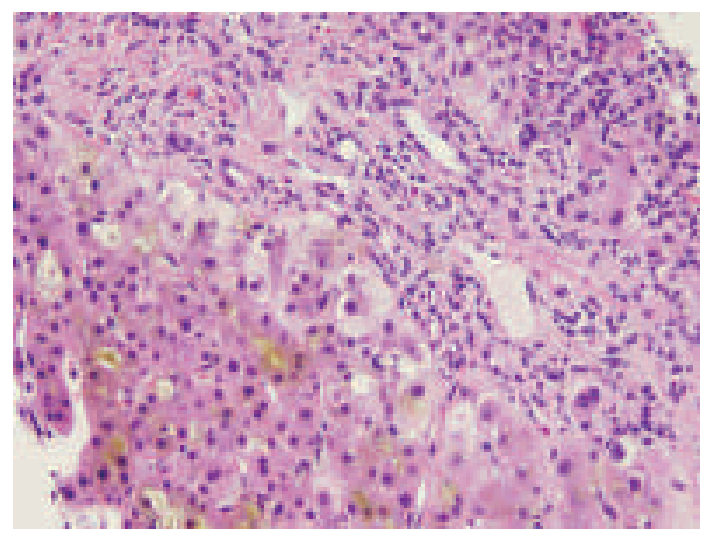

Figure 9 Prolonged cholestasis. Persistence of canalicular bile plugs accompanied by feathery degeneration of periportal hepatocytes (cholate stasis). H\&E, $\times 200$.

primary sclerosing cholangitis radiologically and histologically. Similar injury can occur with other agents such as formaldehyde and sodium chloride injected into hydatid cysts.

\section{GRANULOMATOUS HEPATITIS}

The most common causes of granulomas in the liver are infections, sarcoidosis, primary biliary cirrhosis and drugs (box 2).

Granulomas are uncommon in hepatitis C but can occur in patients treated with interferon. Talc granulomas can occur in intravenous drug users and can be detected by viewing under polarised light. Other systemic granulomatous disease such as chronic metal toxicity (such as beryllium or copper) can also involve the liver. ${ }^{55}$ Finally, a study of granulomatous hepatitis cases over a 13 -year period identified $11 \%$ as idiopathic. ${ }^{79}$ These cases can present with fever of unknown origin and generally respond favourably to steroids.

The granulomas can be present in the portal tracts or the parenchyma and lack necrosis. Unlike in primary biliary cirrhosis, the granulomas are not centred on the bile ducts. Granulomas also can occur with other patterns of liver injury such as acute hepatitis, cholestasis or steatosis.

The term fibrin-ring granuloma has been used for small granulomas that consist of a ring of fibrin arranged around a central fat vacuole (fig 10). Epithelioid histiocytes are present around the ring of fibrin. In atypical cases, the fibrin is

\section{Box 2 Drugs implicated in granulomatous hepatitis}

\section{Antimicrobials}

- Isoniazid, penicillin, sulfonamides, cephalexin, dapsone, dicloxacillin, oxacillin, interferon

\section{Anticonvulsants/antipsychotic agents}

- Phenytoin, diazepam, chlorpropamide, chlorpromazine, procarbazine, carbamazepine

\section{Others}

- Allopurinol, gold, procainamide, quinidine, methyldopa, diclofenac, diltiazem, BCG therapy for cancer, nitrofurantoin, mesalamine, phenylbutazone (veterinary use, use in humans limited due to side effect of aplastic anaemia) ${ }^{78}$

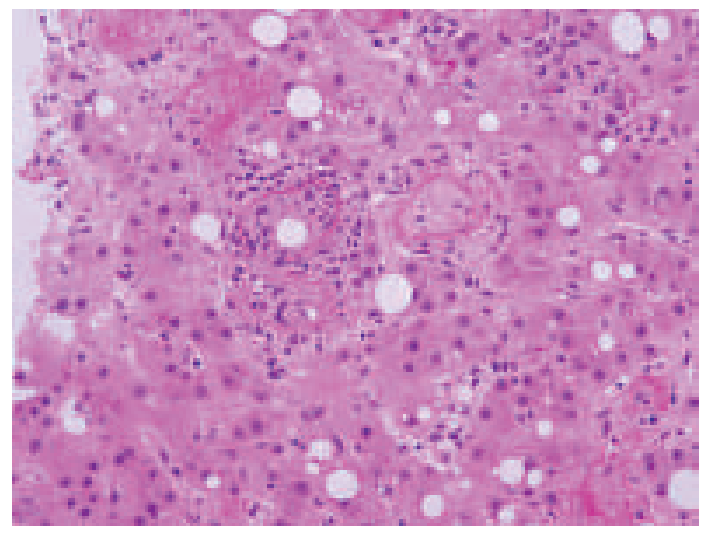

Figure 10 Fibrin-ring granulomas. Fat vacuole surrounded by a ring of fibrin deposition and epithelioid cells. H\&E, $\times 200$.

intermixed with the histiocytes and does not form a welldefined ring. More typical granulomas without the fibrin ring generally are present in other areas of the biopsy. Fibrin-ring granulomas have been described with allopurinol, BCG vaccination and intravesical therapy for carcinoma. These granulomas were first described in the rickettsial disease $\mathrm{Q}$ fever (Coxiella burnetti) but also occur in boutonneuse fever (Rickettsia conorii), leishmaniasis, toxoplasmosis, cytomegalovirus infection and Hodgkin lymphoma.

\section{STEATOSIS AND STEATOHEPATITIS}

\section{Macrovesicular steatosis}

Macrovesicular steatosis includes large and small droplet fat. The term "large droplet fat" is used when at least half the hepatocyte cytoplasm is occupied by a single lipid vacuole, while multiple lipid vacuoles are seen in small droplet fat. The latter often is confused with true microvesicular steatosis which, unlike small droplet fat, affects the liver in a diffuse fashion (see below). Macrovesicular steatosis can be seen in association with steroids, ${ }^{80}$ nitrofurantoin, gold, methotrexate, NSAIDs such as ibuprofen, indomethacin and sulindac, and antihypertensives such as metoprolol, chlorinated hydrocarbons such as carbon tetrachloride and chloroform, ${ }^{81}$ or chemotherapeutic agents such as 5 -fluorouracil, cisplatin and tamoxifen. ${ }^{82}$

\section{Microvesicular steatosis}

Exclusive or predominant microvesicular steatosis diffusely affecting the liver is a result of mitochondrial injury and often occurs as an adverse effect of drugs/toxins such as cocaine, tetracycline, valproic acid and zidovudine (fig 11). Acute exposure to alcohol (alcohol foamy liver degeneration) ${ }^{83}$ and paediatric Reye syndrome also show diffuse microvesicular steatosis. ${ }^{84}$ Other non-drug related aetiologies include acute fatty liver of pregnancy and genetic diseases such as carnitine deficiency.

\section{Steatohepatitis}

By definition, steatohepatitis is characterised by steatosis, lobular inflammation and hepatocellular injury in the form of hepatocellular ballooning (with or without acidophil bodies or Mallory hyaline) or pericellular fibrosis. A few drugs (notably amiodarone and irinotecan) play a direct aetiological role in steatohepatitis. Most other drugs exacerbate or precipitate steatohepatitis in the presence of other risk factors such as obesity and diabetes. 


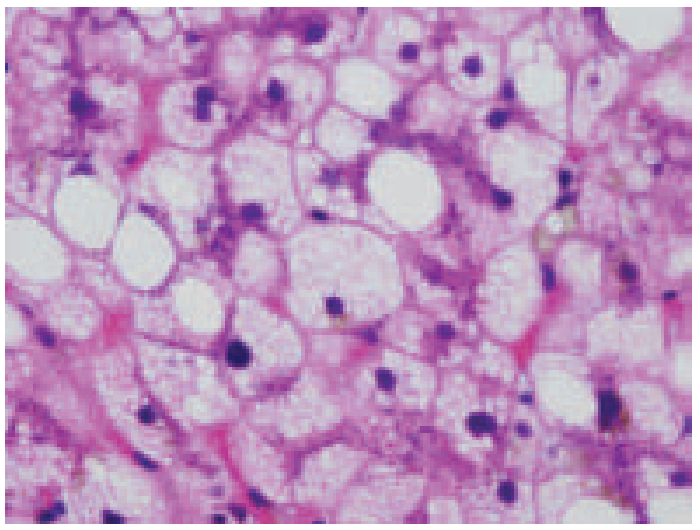

Figure 11 Microvesicular steatosis. Numerous small lipid droplets are present throughout the hepatocytic cytoplasm. H\&E, $\times 400$.

\section{Amiodarone}

Amiodarone, a potent antiarrhythmic agent, causes elevated liver enzymes in up to $30 \%$ of patients ${ }^{85}{ }^{86}$ and steatohepatitis in $1-2 \%{ }^{87}$ of patients. The majority of cases display liver enzyme abnormalities within $24 \mathrm{~h}$ of intravenous infusion. ${ }^{88}$ Even low oral dosing (200 mg daily) may trigger steatohepatitis with cumulative use. ${ }^{89}$ Occasionally, jaundice is the major clinical presentation. These cases often show hepatocellular necrosis and fibrosis, and have a poor prognosis. ${ }^{66}$

Amiodarone steatohepatitis is characterised by prominent Mallory hyaline (occasionally in zone 1) and neutrophilic satellitosis, while steatosis is less conspicuous (fig 12). The findings can be similar to alcoholic steatohepatitis. Reversal of liver injury often occurs with discontinuation of the drug but may be delayed by weeks or months. In addition, amiodarone is also associated with a different type of lipid accumulation called "phospholipidosis" characterised by accumulation of drug in the lysosomes. ${ }^{90} 91$ This leads to "foamy" appearance of hepatocytes and Kupffer cells. The foamy areas show lamellar lysosomal inclusion bodies on electron microscopy ${ }^{92}$ (fig 13). Phospholipidosis is not always seen in amiodarone toxicity ${ }^{90}$ and is independent of steatohepatitis. ${ }^{93}$

Perhexiline maleate (Pexid), an antianginal drug, and diethylaminoethoxyhexestrol (Coralgil), a vasodilator, have been used extensively in Europe and Japan, respectively. Both drugs can cause steatohepatitis and phospholipidosis similar to amiodarone. ${ }^{94} 95$

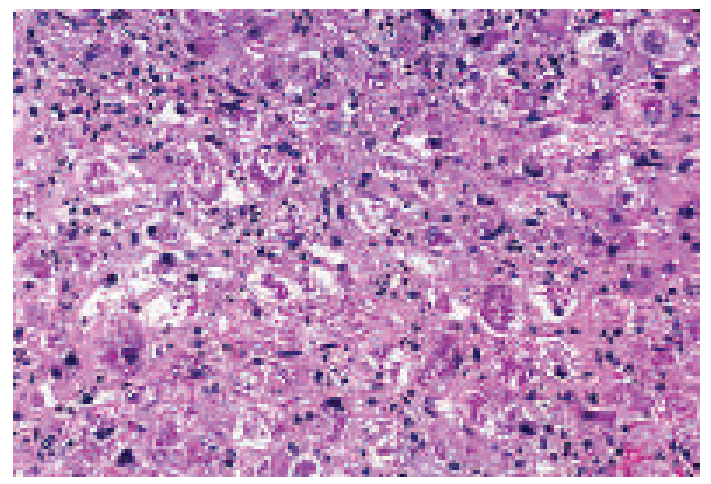

Figure 12 Amiodarone steatohepatitis. Marked hepatocyte ballooning, numerous Mallory hyaline and minimal steatosis. $\mathrm{H \& E}, \times 100$.

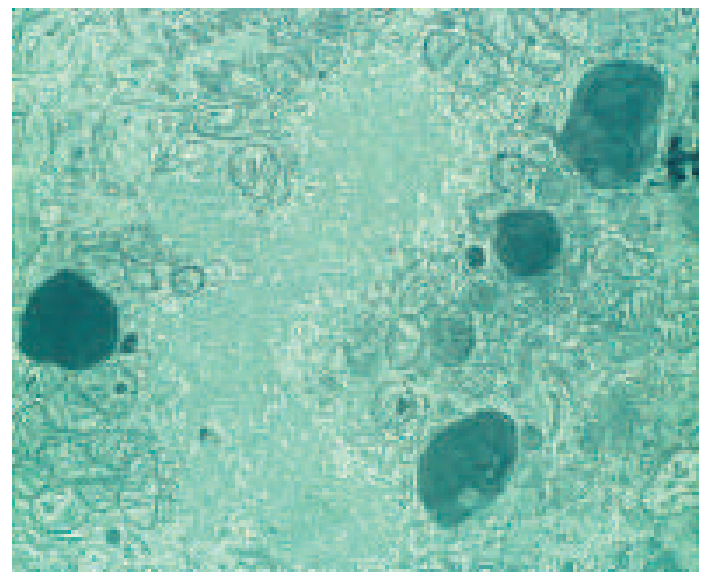

Figure 13 Phospholipidosis. Formation of lysosomal inclusion bodies due to accumulation of amiodarone. Electron micrograph. (Image courtesy of Dr Linda Ferrell, University of California, San Francisco, California, USA.)

\section{Chemotherapy-induced steatohepatitis}

Steatosis and steatohepatitis have been reported with chemotherapeutic agents. The latter especially is associated with irinotecan, a drug often used preoperatively in colorectal cancer with hepatic metastases. This has been referred to as chemotherapy-associated steatohepatitis in the oncology literature. ${ }^{82}$ Other chemotherapeutic agents such as oxaliplatin have been variably implicated. ${ }^{82} 97$

\section{Others}

Drugs such as tamoxifen, steroids, oestrogen and diethylstilbestrol often lead to hepatic steatosis, but steatohepatitis is rare. These drugs may exacerbate or precipitate steatohepatitis in patients with risk factors for steatohepatitis rather than play an aetiological role. The evidence linking steatohepatitis and calcium channel blockers such as nifedipine also is anecdotal. Risk factors for steatohepatitis were present in many reported cases, creating uncertainty about the association of these drugs with steatohepatitic injury. ${ }^{98}$

\section{VASCULAR ABNORMALITIES}

Several vascular patterns of injury are recognised, each with distinctive morphological features and drug associations.

\section{Sinusoidal obstruction syndrome}

Sinusoidal obstruction syndrome (SOS; veno-occlusive disease) is due to endothelial cell injury to small hepatic venules that manifests histologically as endothelial swelling and thrombosis (fig 14). The resultant venous outflow obstruction leads to sinusoidal dilatation, congestion, hepatocellular necrosis, and can result in centrilobular fibrosis.

Cytotoxic/chemotherapeutic drugs such as oxaliplatin (used in colorectal cancer) can cause injury to sinusoidal endothelial cells and hepatic stellate cells. ${ }^{97} 99100$ SOS can also occur due to myeloablation before stem cell transplantation, chemotherapy for acute lymphocytic leukaemia, bone marrow transplantation $^{101}$ and pyrrolizidine alkaloids. ${ }^{97}$ Genetic polymorphisms in methylenetetrahydrofolate reductase have been implicated in SOS in post-transplant patients. ${ }^{102}$ Recently, defibrotide has been used with success to resolve cases of SOS, ${ }^{103}$ although in some cases, transplantation can be required. ${ }^{104}$ 


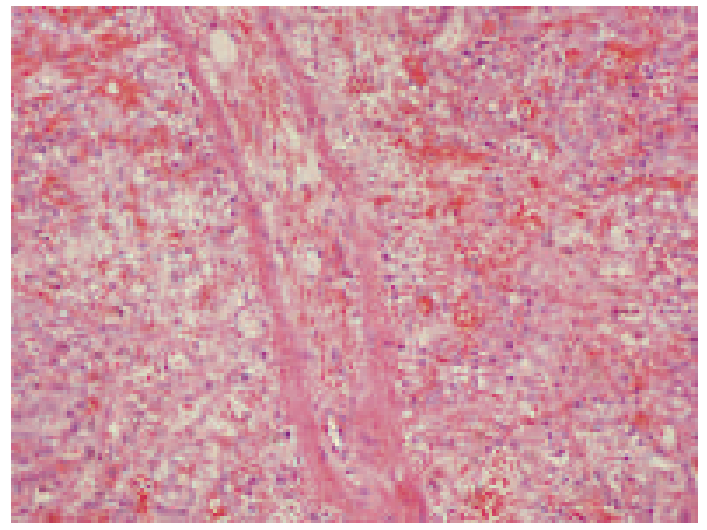

Figure 14 Sinusoidal obstruction syndrome. Endothelial injury in small hepatic venules leads to luminal occlusion due to endothelial swelling and thrombosis, and results in sinusoidal dilatation and congestion. H\&E, $\times 100$.

\section{Peliosis hepatis}

Peliosis is characterised by blood-filled cavities without an endothelial lining in the hepatic parenchyma (fig 15). This phenomenon most commonly is associated with androgens ${ }^{105}$ or contraceptive steroids. ${ }^{106}$ Thiopurine-derived chemotherapeutic drugs also have been implicated. ${ }^{107}{ }^{108}$ Peliosis also occurred with the intravenous contrast agent thorium dioxide (Thorotrast), which has been discontinued due to the high risk of angiosarcoma. ${ }^{109} 110$ Sinusoidal dilatation may accompany peliosis or may occur independently, particularly with androgenic or oestrogenic steroid use. ${ }^{111}$

\section{Hepatic vein thrombosis}

Hepatic vein thrombosis is a rare complication of some drugs, including oral contraceptives ${ }^{112} 113$ and dacarbazine, ${ }^{114}$ and presents clinically as Budd-Chiari syndrome.

\section{OTHER PATTERNS}

\section{Stellate cell lipidosis}

Hepatic stellate cells (Ito cells) are modified fibroblasts that store lipids and vitamin A in the normal liver. They are located in the space of Disse between the sinusoidal endothelium and the hepatocytes but generally are not easily visible. ${ }^{115}$ In certain conditions, especially hypervitaminosis A, excessive lipid gets stored in the stellate cells (stellate cell lipidosis, fig 16). The nuclei of stellate cells are crescent shaped, dark staining, and

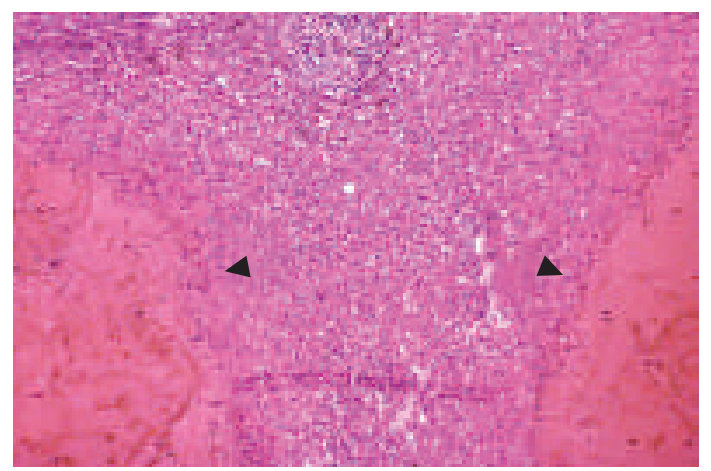

Figure 15 Peliosis. The hepatic parenchyma contains blood-filled cavities that lack an endothelial lining (arrows). H\&E, $\times 66$. (Image courtesy of Dr Linda Ferrell, University of California, San Francisco, California, USA.)

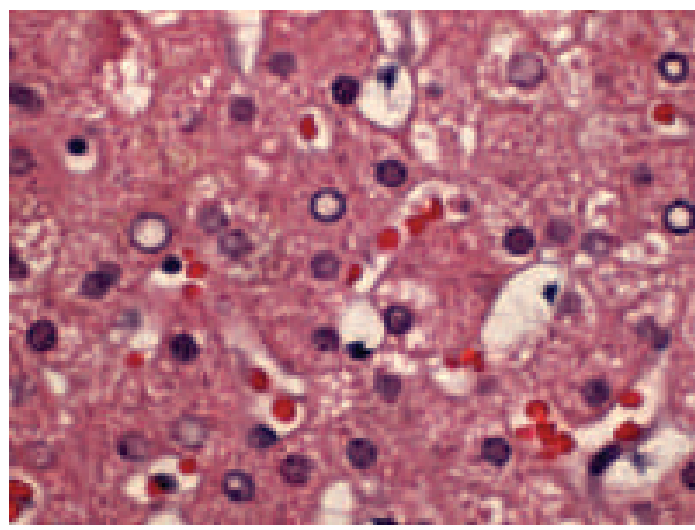

Figure 16 Stellate cell (Ito cell) lipidosis. Fat-laden stellate cells showing multiple lipid vacuoles with indentation of the nucleus. Note the location of Ito cells along the sinusoids in the space of Disse. H\&E, $\times 400$.

indented by the lipid droplets. Thin strands of cytoplasm separate the lipid droplets. These lipid-laden cells easily can be mistaken for hepatocytes with steatosis. Their characteristic morphology and location along the sinusoids between the hepatic plates distinguishes them from steatotic hepatocytes. ${ }^{116}$

Hypervitaminosis A results from excess dietary/supplementary vitamin A intake or use of oral/topical retinoids (such as etretinate for acne). Stellate cell lipidosis also has been reported with methotrexate, valproate and steroids, as well as in other clinical settings such as cholestasis, alcoholic liver disease and hepatitis $C$.

It is important to recognise this condition, as activation of stellate cells can lead to fibrosis, non-cirrhotic portal hypertension and, rarely, cirrhosis. One case of liver transplantation for subacute vitamin A toxicity has been reported. ${ }^{117}$ Early recognition can prompt reduced intake of vitamin A to avert progression and fibrosis. The contribution of stellate cell lipidosis to disease progression when present with other disease processes such as alcoholic liver disease and chronic hepatitis $C$ is unknown.

\section{Cytoplasmic inclusions}

Ground glass change in the cytoplasm occurs in a minority of patients with hepatitis B and is characterised by pale eosinophilic

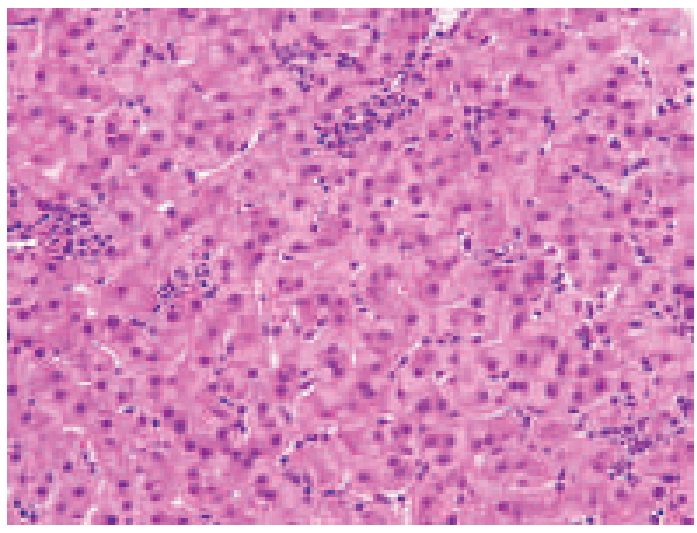

Figure 17 Ground-glass hepatocytes. This change can be seen with drugs such as cyanamide (used for treating alcohol abuse), diazepam and barbiturates, and in patients on insulin or intravenous glucose therapy. H\&E, $\times 200$. 


\section{Take-home messages}

- Drug-induced liver injury can mimic any pattern of primary liver disease. A thorough clinical history, including exposure to herbal, over-the-counter agents and toxins, along with a systematic literature search, is critical to establish the diagnosis.

- Acute hepatitis, with or without cholestasis, is the most common histological pattern of drug-induced liver injury. Drugs such as acetaminophen are the most common cause of acute liver failure in the USA.

- Drug-induced chronic hepatitis is rare, but fibrosis and cirrhosis can occur with drugs such as methotrexate, while autoimmune hepatitis-like disease can result with drugs such as minocycline.

- In some instances, drug-related cholestatic injury can be prolonged and can lead to ductopenia.

- Drug-induced steatohepatitis is a rare phenomenon, but is well known to occur with amiodarone and irinotecan. Many drugs, such as tamoxifen, oestrogenic drugs and nifedipine, can precipitate or exacerbate steatohepatitis in the presence of other risk factors.

\section{Interactive multiple choice questions}

This JCP best practice article has an accompanying set of multiple choice questions (MCOs).

To access the questions, click on BMJ Learning: take this module on BMJ Learning from the content box at the top right and bottom left of the online article. For more information please go to: http:// jcp.bmj.com/education Please note: the MCQs are hosted on BMJ Learning - the best available learning website for medical professionals from the BMJ Group.

If prompted, subscribers must sign into JCP with their journal's username and password. All users must also complete a one-time registration on BMJ Learning and subsequently log in (with a BMJ Learning username and password) on every visit.

cytoplasmic inclusions in hepatocytes. Similar changes (often termed "pseudo ground glass change", fig 17) can be seen with drugs such as cyanamide, a drug used in alcohol treatment programs. ${ }^{118} 119$ This phenomenon has also been described with other drugs such as barbiturates and diazepam, diabetic patients on insulin, and transplant patients on multiple immunosuppressive drugs such as steroids, tacrolimus and mycophenolate mofetil. ${ }^{19} 120$ Similar to hepatitis B, this change reflects hypertrophy of smooth endoplasmic reticulum with use of drugs such as barbiturates, while most other drug-induced cases are due to accumulation of abnormal glycogen. ${ }^{118-120}$ Rare metabolic disorders such as type IV glycogenosis, hypofibrinogenaemia, and Lafora disease can lead to the same morphological findings.

\section{Pigments}

Some drugs/toxins such as gold, titanium and thorium dioxide (Thorotrast) can be deposited as pigments in the liver. Drugs that cause prolonged cholestasis can lead to copper accumulation in periportal hepatocytes. Lipofuscin, a lysosomal pigment often seen in centrizonal hepatocytes, can be increased with exposure to anticonvulsant drugs such as phenothiazine and phenacetin.

\section{Hepar lobatum}

This term generally refers to liver abnormalities in tertiary syphilis. In some instances, chemotherapy for metastatic liver cancer (especially from the breast) can lead to similar changes. The liver shows a lobulated contour with capsular indentations from which fibrous septa extend deep into the parenchyma. ${ }^{121}$ The fibrous septa can surround the degenerated centre of tumour nodules and may contain macrophages and residual tumour. Typical features of cirrhosis such as regenerative nodules are not observed. These features probably result from tissue collapse due to chemotherapy-related tumour regression that is followed by an organising phase of healing and scar contraction. ${ }^{121}$

\section{Drug-related neoplasms}

The association of oral contraceptives and hepatic adenomas is well recognised. ${ }^{122}$ Association with focal nodular hyperplasia and hepatocellular carcinoma also has been reported, ${ }^{123}{ }^{124}$ but the link is less convincing. Other agents such as anabolic steroids used by sportsmen, clomiphene, danazol and carbamazepine have also been associated with hepatic adenoma. ${ }^{125} 126$

Exposure to vinyl chloride (an industrial chemical) and thorium dioxide (a discontinued radiographic contrast agent) can lead to angiosarcoma, sometimes after long latent periods exceeding 20 years. ${ }^{127}$ Hepatocellular carcinoma and cholangiocarcinoma also have been reported with thorium dioxide. ${ }^{128}$

Competing interests: None.

\section{REFERENCES}

1. Watkins PB, Seeff LB. Drug-induced liver injury: summary of a single topic clinical research conference. Hepatology 2006;43:618-31.

2. Teschke R, Schwarzenboeck A, Hennermann KH. Kava hepatotoxicity: a clinical survey and critical analysis of 26 suspected cases. Eur J Gastroenterol Hepatol 2008;20:1182-93.

3. Danan G, Benichou C. Causality assessment of adverse reactions to drugs. I. A novel method based on the conclusions of international consensus meetings: application to drug-induced liver injuries. J Clin Epidemiol 1993;46:1323-30.

4. Benichou C, Danan G, Flahault A. Causality assessment of adverse reactions to drugs. II. An original model for validation of drug causality assessment methods: case reports with positive rechallenge. J Clin Epidemiol 1993;46:1331-6.

5. Andrade RJ, Lucena Ml, Fernández MC, et al. Drug-induced liver injury: an analysis of 461 incidences submitted to the Spanish registry over a 10-year period. Gastroenterology 2005;129:512-21.

6. Zimmerman HJ. Drug-induced liver disease. Clin Liver Dis 2000:4:73-96.

7. Björnsson $\mathbf{E}$, Olsson R. Suspected drug-induced liver fatalities reported to the WHO database. Dig Liver Dis 2006;38:33-8.

8. Velayudham LS, Farrell GC. Drug-induced cholestasis. Expert Opin Drug Saf 2003;2:287-304.

9. Hartleb M, Biernat L, Kochel A. Drug-induced liver damage - a three-year study of patients from one gastroenterological department. Med Sci Monit 2002;8:CR292-6.

10. Memorial Sloan-Kettering Cancer Center. About herbs, botanicals and other products. http://www.mskcc.org/mskcc/html/58481.cfm laccessed 18 February 2009).

11. United States Department of Agriculture. Natural Resources Conservation Service. PLANTS database. http://plants.usda.gov/index.html (accessed 18 February 2009).

12. Batchelor WB, Heathcote J, Wanless IR. Chaparral-induced hepatic injury. Am J Gastroenterol 1995;90:831-3.

13. Savvidou S, Goulis J, Giavazis I, et al. Herb-induced hepatitis by Teucrium polium $L .:$ report of two cases and review of the literature. Eur J Gastroenterol Hepatol 2007:19:507-11.

14. Larrey D, Vial T, Pauwels A, et al. Hepatitis after germander (Teucrium chamaedrys) administration: another instance of herbal medicine hepatotoxicity. Ann Intern Med 1992;117:129-32.

15. Bakerink JA, Gospe SM Jr, Dimand RJ, et al. Multiple organ failure after ingestion of pennyroyal oil from herbal tea in two infants. Pediatrics 1996;98:944-7.

16. Stickel F, Egerer G, Seitz HK. Hepatotoxicity of botanicals. Public Health Nutr 2000; 3:113-24 
17. Woolf GM, Petrovic LM, Rojter SE, et al. Acute hepatitis associated with the Chinese herbal product jin bu huan. Ann Intern Med 1994;121:729-35.

18. Brown AC, Onopa J, Holck P, et al. Traditional kava beverage consumption and liver function tests in a predominantly Tongan population in Hawaii. Clin Toxicol (Phila) 2007:45:549-56.

19. Harvey J, Colin-Jones DG. Mistletoe hepatitis. Br Med J (Clin Res Ed) 1981:282:186-7.

20. Li B, Wang Z, Fang JJ, et al. Evaluation of prognostic markers in severe druginduced liver disease. World J Gastroenterol 2007:13:628-32.

21. Tilburt JC, Kaptchuk TJ. Herbal medicine research and global health: an ethical analysis. Bull World Health Organ 2008;86:594-9.

22. O'Sullivan HM, Lum K. The poisoning of 'awa: the non-traditional use of an ancient remedy. Pac Health Dialog 2004;11:211-5.

23. Ashar BH, Rice TN, Sisson SD. Medical residents' knowledge of dietary supplements. South Med J 2008;101:996-1000.

24. Lukita-Atmadja W, Ito Y, Baker GL, et al. Effect of curcuminoids as antiinflammatory agents on the hepatic microvascular response to endotoxin. Shock 2002:17:399-403.

25. Martins F, Suzan AJ, Cerutti SM, et al. Consumption of mate tea (/lex paraguariensis) decreases the oxidation of unsaturated fatty acids in mouse liver Br J Nutr 2008;19:1-6.

26. Wai CT, Tan $\mathrm{BH}$, Chan $\mathrm{CL}$, et al. Drug-induced liver injury at an Asian center: a prospective study. Liver Int 2007;27:465-74

27. Williams R. Classification, etiology, and considerations of outcome in acute liver failure. Semin Liver Dis 1996;16:343-8.

28. Lee WM. Acute liver failure. Clin Perspect Gastroenterol 2001;2:101-10.

29. Williams R. Changing clinical patterns in acute liver failure. J Hepatol 2003:39:660-1.

30. Hanje AJ, Chalasani N. How common is chronic liver disease from acute druginduced liver injury? Gastroenterology 2007;132:2067-8;discussion 2068-9.

31. Russo MW, Galanko JA, Shrestha R, et al. Liver transplantation for acute liver failure from drug induced liver injury in the United States. Liver Transpl 2004; 10:1018-23.

32. Saukkonen JJ, Cohn DL, Jasmer RM, et al. An Official ATS Statement: Hepatotoxicity of Antituberculosis Therapy. Am J Respir Crit Care Med 2006;174:935-52

33. Larson AM, Polson J, Fontana RJ, et al. Acetaminophen-induced acute liver failure: results of a United States multicenter, prospective study. Hepatology 2005:42:1364-72

34. Batts KP, Ludwig J. Chronic hepatitis. An update on terminology and reporting. Am J Surg Pathol 1995;19:1409-17.

35. Bénichou C. Criteria of drug-induced liver disorders. Report of an internationa consensus meeting. J Hepatol 1990;11:272-6

36. Andrade RJ, Lucena MI, Kaplowitz N, et al. Outcome of acute idiosyncratic druginduced liver injury: Long-term follow-up in a hepatotoxicity registry. Hepatology 2006;44:1581-8

37. Roy AK, Mahoney HC, Levine RA. Phenytoin-induced chronic hepatitis. Dig Dis Sci 1993:38:740-3

38. Picciotto A, Campo N, Brizzolara R, et al. Chronic hepatitis induced by Jin Bu Huan. J Hepatol 1998:28:165-7.

39. Saleh F, Ko HH, Davis JE, et al. Fatal hepatitis C associated fibrosing cholestatic hepatitis as a complication of cyclophosphamide and corticosteroid treatment of active glomerulonephritis. Ann Hepatol 2007;6:186-9.

40. Goldstein NS, Bayati N, Silverman AL, et al. Minocycline as a cause of druginduced autoimmune hepatitis. Report of four cases and comparison with autoimmune hepatitis. Am J Clin Pathol 2000;114:591-8.

41. Ford TJ, Dillon JF. Minocycline hepatitis. Eur J Gastroenterol Hepatol 2008;20:796-9.

42. Amit G, Cohen P, Ackerman Z. Nitrofurantoin-induced chronic active hepatitis. Isr Med Assoc J 2002;4:184-6.

43. Stricker BH, Blok AP, Claas FH, et al. Hepatic injury associated with the use of nitrofurans: a clinicopathological study of 52 reported cases. Hepatology 1988;8:599-606.

44. Arranto AJ, Sotaniemi EA. Histologic follow-up of $\alpha$-methyldopa-induced liver injury. Scand J Gastroenterol 1981;16:865-72.

45. Islam S, Mekhloufi F, Paul JM, et al. Characteristics of clometacin-induced hepatitis with special reference to the presence of anti-actin cable antibodies. Autoimmunity 1989;2:213-21.

46. Mizutani T, Shinoda M, Tanaka Y, et al. Autoantibodies against CYP2D6 and other drug-metabolizing enzymes in autoimmune hepatitis type 2. Drug Metab Rev 2005;37:235-52.

47. Hytiroglou $\mathbf{P}$, Tobias $H$, Saxena $\mathrm{R}$, et al. The canals of hering might represent a target of methotrexate hepatic toxicity. Am J Clin Pathol 2004;121:324-9.

48. Whiting-0'Keefe $\mathbf{0 E}$, Fye $\mathbf{K H}$, et al. Methotrexate and histologic hepatic abnormalities: a meta-analysis. Am J Med 1991;90:711-6.

49. Langman G, Hall PM, Todd G. Role of non-alcoholic steatohepatitis in methotrexate-induced liver injury. J Gastroenterol Hepatol 2001;16:1395-401.

50. Roenigk HH Jr, Auerbach R, Maibach HI, et al. Methotrexate in psoriasis: revised guidelines. J Am Acad Dermatol 1988;19:145-56.

51. Roenigk HH Jr, Auerbach $\mathrm{R}$, Maibach $\mathrm{H}$, et al. Methotrexate in psoriasis consensus conference. J Am Acad Dermatol 1998;38:478-85.

52. Berends MA, van Oijen MG, Snoek J, et al. Reliability of the Roenigk classification of liver damage after methotrexate treatment for psoriasis: a clinicopathologic study of 160 liver biopsy specimens. Arch Dermatol 2007;143:1515-9.
53. Friis H, Andreasen PB. Drug-induced hepatic injury: an analysis of 1100 cases reported to the Danish Committee on Adverse Drug Reactions between 1978 and 1987. J Int Med 1992;232:133-8.

54. Bion E, Pariente EA, Maitre F. Severe cholestasis and sicca syndrome after thiabendazole. J Hepatol 1995;23:762-3.

55. Ishak KG, Zimmerman HJ. Drug-induced and toxic granulomatous hepatitis. Baillieres Clin Gastroenterol 1988;2:463-80.

56. Karthik SV, Casson D. Erythromycin-associated cholestatic hepatitis and liver dysfunction in children: the British experience. J Clin Gastroenterol 2005:39:743-4.

57. Van Mil SW, van der Woerd WL, van der Brugge G, et al. Benign recurrent intrahepatic cholestasis type 2 is caused by mutations in ABCB11. Gastroenterology 2004; 127:379-84

58. Dixon PH, van Mil S, Chambers J, et al. Contribution of variant alleles of ABCB11 to susceptibility to intrahepatic cholestasis of pregnancy. Gut. Published Online First: 5 November 2008. doi:10.1136/gut.2008.159541

59. Degott C, Feldmann G, Larrey D, et al. Drug-induced prolonged cholestasis in adults: a histological semiquantitative study demonstrating progressive ductopenia. Hepatology 1992:15:244-51.

60. Pedro-Botet J, Supervía A, Barranco C, et al. Intrahepatic cholestasis without hepatitis induced by amoxicillin/clavulanic acid. J Clin Gastroenterol 1996;23:137-8.

61. Larrey D, Vial T, Micaleff A, et al. Hepatitis associated with amoxicillin-clavulanic acid combination: report of 15 cases. Gut 1992;33:368-71.

62. Olsson R, Wilholm BE, Sand C, et al. Liver damage from flucloxacillin, cloxacillin and dicloxacillin. J Hepatol 1992;15:154-61.

63. Fairley CK, McNeil JJ, Desmond P, et al. Risk factors for development of flucloxacillin associated jaundice. BMJ 1993:306:233-5.

64. Mallat A, Zafrani ES, Metreau JM, et al. Terbinafine-induced prolonged cholestasis with reduction of interlobular bile ducts. Dig Dis Sci 1997:42:1486-8.

65. Wedén M, Glaumann H, Einarsson K. Protracted cholestasis probably induced by oral contraceptive. J Intern Med 1992;231:561-5

66. Chang CC, Petrelli M, Tomashefski JF Jr, et al. Severe intrahepatic cholestasis caused by amiodarone toxicity after withdrawal of the drug: a case report and review of the literature. Arch Pathol Lab Med 1999;123:251-6.

67. Forbes GM, Jeffrey GP, Shilkin KB, et al. Carbamazepine hepatotoxicity: another cause of the vanishing bile duct syndrome. Gastroenterology 1992;102:1385-8.

68. Vuppalanchi R, Chalasani N, Saxena R. Restoration of bile ducts in drug-induced vanishing bile duct syndrome due to zonisamide. Am J Surg Pathol 2006;30:1619-23.

69. Moradpour D, Altorfer J, Flury R, et al. Chlorpromazine-induced vanishing bile duct syndrome leading to biliary cirrhosis. Hepatology 1994:20:1437-41.

70. Villari D, Rubino F, Corica F, et al. Bile ductopenia following therapy with sulpiride. Virchows Arch 1995;427:223-6.

71. Taghian M, Tran TA, Bresson-Hadni S, et al. Acute vanishing bile duct syndrome after ibuprofen therapy in a child. J Pediatr 2004;145:273-6.

72. Alam I, Ferrell LD, Bass NM. Vanishing bile duct syndrome temporally associated with ibuprofen. Am J Gastroenterol 1996:91:1626-30.

73. Trak-Smayra V, Cazals-Hatem D, Asselah T, et al. Prolonged cholestasis and ductopenia associated with tenoxicam. J Hepatol 2003;39:125-8.

74. Davies MH, Harrison RF, Elias E, et al. Antibiotic-associated acute vanishing bile duct syndrome: a pattern associated with severe, prolonged, intrahepatic cholestasis. J Hepatol 1994:20:112-6.

75. Eckstein RP, Dowsett JF, Lunzer MR. Flucloxacillin induced liver disease: histopathological findings at biopsy and autopsy. Pathology 1993;25:223-8.

76. Altraif I, Lilly L, Wanless IR, et al. Cholestatic liver disease with ductopenia (vanishing bile duct syndrome) after administration of clindamycin and trimethoprimsulfamethoxazole. Am J Gastroenterol 1994;89:1230-4.

77. Alazmi WM, McHenry L, Watkins JL, et al. Chemotherapy-induced sclerosing cholangitis: long-term response to endoscopic therapy. J Clin Gastroenterol 2006;40:353-7.

78. Benjamin SB, Ishak KB, Zimmerman HJ, et al. Phenylbutazone liver injury: a clinical-pathologic survey of 23 cases and review of the literature. Hepatology 1981:1:255-63.

79. McCluggage WG, Sloan JM. Hepatic granulomas in Northern Ireland: a thirteen year review. Histopathology 1994;25:219-28.

80. Paquot N, Delwaide J. Fatty liver in the intensive care unit. Curr Opin Clin Nutr Metab Care 2005:8:183-7.

81. Plaa GL. Chlorinated methanes and liver injury: highlights of the past 50 years Annu Rev Pharmacol Toxicol 2000;40:42-65.

82. Zorzi D, Laurent A, Pawlik TM, et al. Chemotherapy-associated hepatotoxicity and surgery for colorectal liver metastases. Br J Surg 2007;94:274-86.

83. Uchida T, Kao H, Quispe-Sjogren $\mathrm{M}$, et al. Alcoholic foamy degeneration - a pattern of acute alcoholic injury of the liver. Gastroenterology 1983:84:683-92.

84. Kimura S, Kobayashi T, Tanaka Y, et al. Liver histopathology in clinical Reye syndrome. Brain Dev 1991;13:95-100.

85. Vassallo P, Trohman RG. Prescribing amiodarone: an evidence-based review of clinical indications. JAMA 2007:298:1312-22.

86. Lewis JH, Ranard RC, Caruso A, et al. Amiodarone hepatotoxicity: prevalence and clinicopathologic correlations among 104 patients. Hepatology:9:679-85.

87. Stravitz RT, Sanyal AJ. Drug-induced steatohepatitis. Clin Liver Dis 2003;7:435-51.

88. Rätz Bravo AE, Drewe J, Schlienger RG, et al. Hepatotoxicity during rapid intravenous loading with amiodarone: Description of three cases and review of the literature. Crit Care Med 2005;33:128-34;discussion 245-6.

89. Babany G, Mallat A, Zafrani ES, et al. Chronic liver disease after low daily doses of amiodarone. Report of three cases. J Hepatol 1986:3:228-32. 
90. Lewis $\mathbf{J H}$, Mullick F, Ishak KG, et al. Histopathologic analysis of suspected amiodarone hepatotoxicity. Hum Pathol 1990;21:59-67.

91. Richert M, Robert S. Fatal hepatotoxicity following oral administration of amiodarone. Ann Pharmacother 1995;29:582-6.

92. Rigas B, Rosenfeld LE, Barwick KW, et al. Amiodarone hepatotoxicity. A clinicopathologic study of five patients. Ann Intern Med 1986:104:348-51.

93. Guigui B, Perrot S, Berry JP, et al. Amiodarone-induced hepatic phospholipidosis: a morphological alteration independent of pseudoalcoholic liver disease. Hepatology:8:1063-8.

94. Pessayre D, Bichara M, Degott C, et al. Perhexiline maleate-induced cirrhosis. Gastroenterology 1979;76:170-7.

95. Le Gall JY. Perhexiline maleate toxicity on human liver cell lines. Gut 1980;21:977-84.

96. Pawlik TM, Olino K, Gleisner AL, et al. Preoperative chemotherapy for colorectal liver metastases: impact on hepatic histology and postoperative outcome. J Gastrointest Surg 2007:11:860-8.

97. Kandutsch S, Klinger M, Hacker S, et al. Patterns of hepatotoxicity after chemotherapy for colorectal cancer liver metastases. Eur J Surg Oncol 2008:34:1231-6.

98. Bruno S, Maisonneuve P. Castellana P. et al. Incidence and risk factors for nonalcoholic steatohepatitis: prospective study of 5408 women enrolled in Italian tamoxifen chemoprevention trial. BMJ 2005;330:932.

99. Karoui M, Penna C, Amin-Hashem M, et al. Influence of preoperative chemotherapy on the risk of major hepatectomy for colorectal liver metastases. Ann Surg 2006:243:1-7.

100. Nordlinger B, Benoist S. Benefits and risks of neoadjuvant therapy for liver metastases. J Clin Oncol 2006;24:4954-5.

101. Kumar S, DeLeve LD, Kamath PS, et al. Hepatic veno-occlusive disease (sinusoidal obstruction syndrome) after hematopoietic stem cell transplantation. Mayo Clin Proc 2003:78:589-98.

102. Goekkurt E, Stoehlmacher J, Stueber C, et al. Pharmacogenetic analysis of liver toxicity after busulfan/cyclophosphamide-based allogeneic hematopoietic stem cell transplantation. Anticancer Res 2007:27:4377-80.

103. Ho VT, Revta C, Richardson PG. Hepatic veno-occlusive disease after hematopoietic stem cell transplantation: update on defibrotide and other current investigational therapies. Bone Marrow Transplant 2008;41:229-37.

104. Membreno FE, Ortiz J, Foster PF, et al. Liver transplantation for sinusoidal obstructive syndrome (veno-occlusive disease): case report with review of the literature and the UNOS database. Clin Transplant 2008;22:397-404.

105. Tsirigotis $\mathbf{P}$, Sella T, Shapira MY, et al. Peliosis hepatitis following treatment with androgen-steroids in patients with bone marrow failure syndromes. Haematologica 2007:92:e106-10.

106. Perarnau JM, Bacq Y. Hepatic vascular involvement related to pregnancy, oral contraceptives, and estrogen replacement therapy. Semin Liver Dis 2008;28:315-27.

107. Elsing C, Placke J, Herrman T. Alcohol binging cause peliosis hepatitis during azathioprine therapy in Crohn's disease. World J Gastroenterol 2007;13:4646-8.
108. Gisbert JP, González-Lama Y, Maté J. Thiopurine-induced liver injury in patients with inflammatory bowel disease: a systematic review. Am J Gastroenterol 2007:102:1518-27.

109. Okuda K, Omata M, Itoh $\mathrm{Y}$, et al. Peliosis hepatitis as a late and fatal complication of thorotrast liver disease. Report of five cases. Liver 1981;1:110-22.

110. Falk H, Thomas LB, Popper $H$, et al. Hepatic angiosarcoma associated with androgenic-anabolic steroids. Lancet 1979:2:1120-3.

111. Oligny LL, Lough J. Hepatic sinusoidal ectasia. Hum Pathol 1992;23:953-6.

112. Akbas T, Imeryüz N, Bayalan F, et al. A case of Budd-Chiari syndrome with Behcet's disease and oral contraceptive usage. Rheumatol Int 2007:28:83-6.

113. Srinivasan P, Rela M, Prachalias A, et al. Liver transplantation for Budd-Chiari syndrome. Transplantation 2002; 73:973-7.

114. Herishanu $\mathbf{Y}$, Lishner M, Kitay-Cohen Y. The role of glucocorticoids in the treatment of fulminant hepatitis induced by dacarbazine. Anticancer Drugs 2002;13:177-9.

115. Friedman SL. Hepatic stellate cells: protean, multifunctional, and enigmatic cells of the liver. Physiol Rev 2008;88:125-72.

116. Levine PH, Delgado Y, Theise ND, et al. Stellate-cell lipidosis in liver biopsy specimens. Recognition and significance. Am J Clin Pathol 2003:119:254-8.

117. Cheruvattath R, Orrego M, Gautam M, et al. Vitamin A toxicity: when one a day doesn't keep the doctor away. Liver Transp/ 2006;12:1888-91.

118. Wisell J, Boitnott J, Haas M, et al. Glycogen pseudoground glass change in hepatocytes. Am J Surg Pathol 2006;30:1085-90.

119. Lefkowitch JH, Lobritto SJ, Brown RS Jr, et al. Ground-glass, polyglucosan-like hepatocellular inclusions: A "new" diagnostic entity. Gastroenterology 2006;131:713-8

120. Alonso-Marti C, Moreno A, Barat A, et al. Co-existence of hepatocyte groundglass inclusions from several causes. Histopathology 1990;16:304-7.

121. Gravel DH, Bégin LR, Brisson ML, et al. Metastatic carcinoma resulting in hepar lobatum. Am J Clin Pathol 1996:105:621-7.

122. Edmondson HA, Henderson B, Benton B. Liver cell adenomas associated with use of oral contraceptives. N Engl J Med 1976;294:470-2.

123. Tao L. Oral contraceptive-associated liver cell adenoma and hepatocellular carcinoma: Cytomorphology and mechanism of malignant transformation. Cancer 1991:68:341-7.

124. Laurent C, Trillaud H, Lepreux S, et al. Association of adenoma and focal nodular hyperplasia: experience of a single French academic center. Comp Hepatol 2003;2:6.

125. Bork K, Pitton M, Harten P, et al. Hepatocellular adenomas in patients taking danazol for hereditary angio-oedema. Lancet 1999;353:1066-7.

126. Tazawa K, Yasuda M, Ohtani Y, et al. Multiple hepatocellular adenomas associated with long-term carbamezapine. Histopathology 1999;35:92-4.

127. Lipshutz GS, Brennan TV, Warren RS. Thorotrast-induced liver neoplasia: a collective review. J Am Coll Surg 2002;195:713-8.

128. Mori T, Fukutomi K, Kato Y, et al. 1998 results of the first series of follow-up studies on Japanese thorotrast patients and their relationships to an autopsy series. Radiat Res 1999;152:S72-80. 
8. Andersen RV, Tybjaerg-Hansen A, Appleyard M, et al. Haemochromatosis mutations in the general population; iron overload progression rate. Blood 2004;103:2914-19.

9. Olynyk JK, Hagan SE, Cullen DJ, et al. Evolution of untreated hereditary haemochromatosis in the Busselton population; a 17 year study. Mayo Clin Proc 2004;79:309-13.
10. Guyander D, Jacquelinet C, Moirland R, et al. Non invasive prediction of fibrosis in $\mathrm{C} 282 \mathrm{Y}$ homozygous haemochromatosis. Gastroenterology 1998;115:929-36.

11. European Association for the Study of the Liver (EASL). EASL clinical practice guidelines for HFE haemochromatosis. J Hepatol. Published Online First: 18 April 2010. doi:10.1016/j.jhep.2010.03.001.

\section{Corrections}

Ramachandran R, Kakar S. Histological patterns in drug-induced liver disease. J Clin Pathol 2009;62:481-92. Table 4 in this article should read as below:

Table 4 Roenigk classification system51

\begin{tabular}{lllll}
\hline Roenigk grade & Fatty change & Nuclear pleomorphism & Necroinflammatory damage & Fibrosis \\
\hline I & Mild or none & Mild or none & Mild or none & None \\
II & Moderate or severe & Moderate or severe & $\begin{array}{l}\text { Moderate or severe portal } \\
\text { inflammation }\end{array}$ & Portal tract expansion \\
IIla & With or without & With or without & With or without & Mild \\
IIIb & With or without & With or without & With or without & Moderate or severe \\
IV & With or without & With or without & With or without & Cirrhosis \\
\hline
\end{tabular}

J Clin Pathol 2010:63:1126. doi:10.1136/jcp.2010.058248corr1

Shih-Sung Chuang, Yung-Liang Liao, Sheng-Tsung Chang, et al. Hepatitis C virus infection is significantly associated with malignant lymphoma in Taiwan, particularly with nodal and splenic marginal zone lymphomas. J Clin Pathol 2010;63:595-8. Table 2 in this article should read as the following:

Table 2 HCV infection status among patients with lymphoma and healthy controls

\begin{tabular}{llll}
\hline Variable & Lymphoma cases $(\mathbf{n = 4 1 8})$ & Healthy controls $(\mathbf{n = 8 2 4 )}$ & $\mathbf{p}$ Value \\
\hline Age (years)† & $57.9 \pm 17.6$ & $46.6 \pm 11.1$ & $<0.001$ \\
Gender, male/female* $_{\text {Anti-HCV negative* }}$ & $265(63.4) / 153(36.6)$ & $496(60.2) / 328(39.8)$ & 0.274 \\
Anti-HCV positive* $^{*}$ & $308(89.0)$ & $809(98.2)$ & $<0.001$ \\
\hline
\end{tabular}

$*^{2}$ test.

tStudent's test.

HCV, hepatitis C virus.

J Clin Pathol 2010:63:1126. doi:10.1136/jcp.2010.076810corr1

Craig S, Tait N. Multiple gastric calculi: a rare cause of gastric outlet obstruction. J Clin Pathol 2010;63:753-4. The author names Craig Steven and Tait Noel are incorrect. They should read as Steven Craig and Noel Tait.

J Clin Pathol 2010:63:1126. doi:10.1136/jcp.2010.077487corr1 